\title{
PHENOTYPIC CHARACTERIZATION AND ANTIFUNGAL SUSCEPTIBILITY PATTERN OF CANDIDA SP ISOLATED FROM A TERTIARY CARE CENTER
}

\author{
Rudramurthy K. G1 ${ }^{1}$ Ramya Kumaran², Geetha R. K³
}

\section{HOW TO CITE THIS ARTICLE:}

Rudramurthy K. G, Ramya Kumaran, Geetha R. K. "Phenotypic Characterization and Antifungal Susceptibility Pattern of Candida SP Isolated from a Tertiary Care Center". Journal of Evolution of Medical and Dental Sciences 2014; Vol. 3, Issue 09, March 3; Page: 2094-2097, DOI: 10.14260/jemds/2014/2108

ABSTRACT: Candida, a yeast like ubiquitous fungus, is an endogenous species which produces commonest fungal infection; Candidiasis. Resistance to antifungal agents is an alarming sign for the emerging common nosocomial candidiasis. MATERIALS AND METHODS: Various types of specimens were collected from the clinically suspected cases of candidiasis. Isolation and characterization of candida sp. was done by standard procedures. Antifungal susceptibility was done by disc diffusion method. RESULT: The candida was isolated from various clinical specimens, vaginal swab (24.66\%), skin scraping (13.33\%) oral swabs (12.66\%), ear swabs (11.33\%), nail scraping (10\%), and pus from diabetes foot ulcer and post-operative wound infection (8\%), sputum (6\%), urine (4.66\%), stool (4\%), blood (2.66\%), and eye swabs (2.66\%). Among different species of candida isolated C.albicans was the predominant species (79.33\%) followed by C tropicalis (19.33\%) and C.Guilliermondii $(1.33 \%)$. Antifungal resistance of different species of candida was higher to fluconazole. The least resistance was seen with amphotericin- B (1.33\%). CONCLUSION: The increased isolation of candida species and development of resistance to commonly used antifungal drugs requires careful interpretation and the in vitro susceptibility testing. This facilitates better patient care.

KEYWORDS: Phenotypic characterization, antifungal susceptibility, Candida sp.

INTRODUCTION: Candida is a normal inhabitant in the skin, mucous membrane of the mouth, respiratory track or vagina, but may invade the other parts of the body, especially in immunecompromised individuals ${ }^{1}$. The most important pathogenic species are C. albicans, $\mathrm{C}$ tropicalis, $\mathrm{C}$ kruseii, $\mathrm{C}$ glabrata, $\mathrm{C}$ lusitaniae, $\mathrm{C}$ viswanathii ${ }^{2}$. They may cause simple lesions to even life threatening systemic infections. The most common species is C. albicans, even though there has been a striking increase in the frequency with non-albicans Candida in the last few years. At present there is increase in reports of treatment failure, may be because of drug resistance, mainly in non-albicans Candida. Invitro susceptibility testing of anti-fungal agents is becoming increasingly important because of introduction of new anti-fungal agents and the recovery of clinical isolates that exhibit inherent or developed resistance to available anti-fungal ${ }^{3,4}$.

OBJECTIVES: To study the prevalence of candida species in clinical specimens and to determine their anti-fungal susceptibility pattern.

MATERIAL \& METHODS: Sterile swabs and bottles were used to collect the appropriate clinical materials. The various clinical specimens collected were oral swabs, ear swabs, vaginal swabs, stool, CSF, sputum, blood, pus, nail scraping etc. The specimen was labeled completely. 


\section{ORIGINAL ARTICLE}

\section{$\underline{\text { Identification Flow Chart }}$}

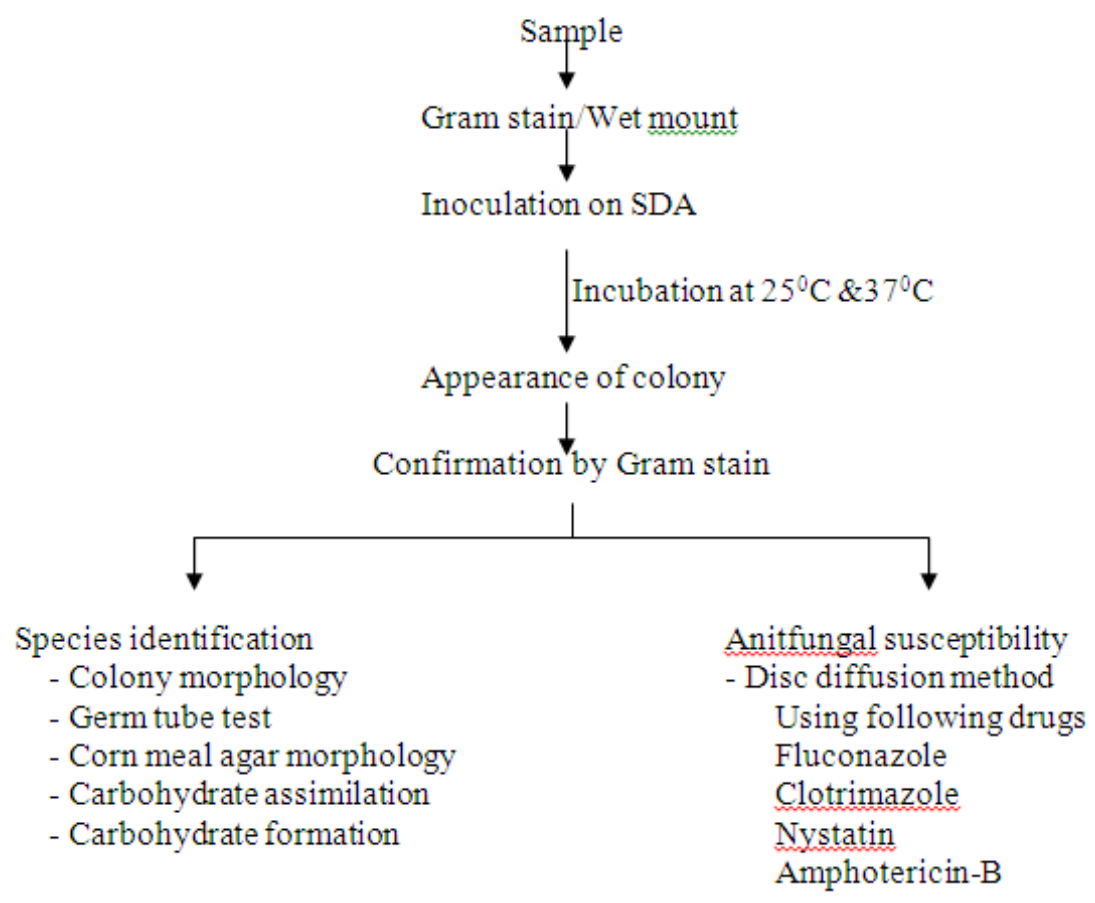

RESULT: Total 150 Candida species were isolated from various clinical specimens. The highest numbers of samples were from vulvo-vaginitis, accounting for $24.66 \%$ of the cases, followed by samples from skin lesion, (13.33\%), oral thrush (12.66\%), CSOM (11.33\%), nail scraping (10\%), pus from diabetic foot and post-operative wound infection (8\%), sputum (6\%), Urine (4.66\%), stool (4\%), and blood (4\%) and eye swabs (4\%) (Fig: 1).

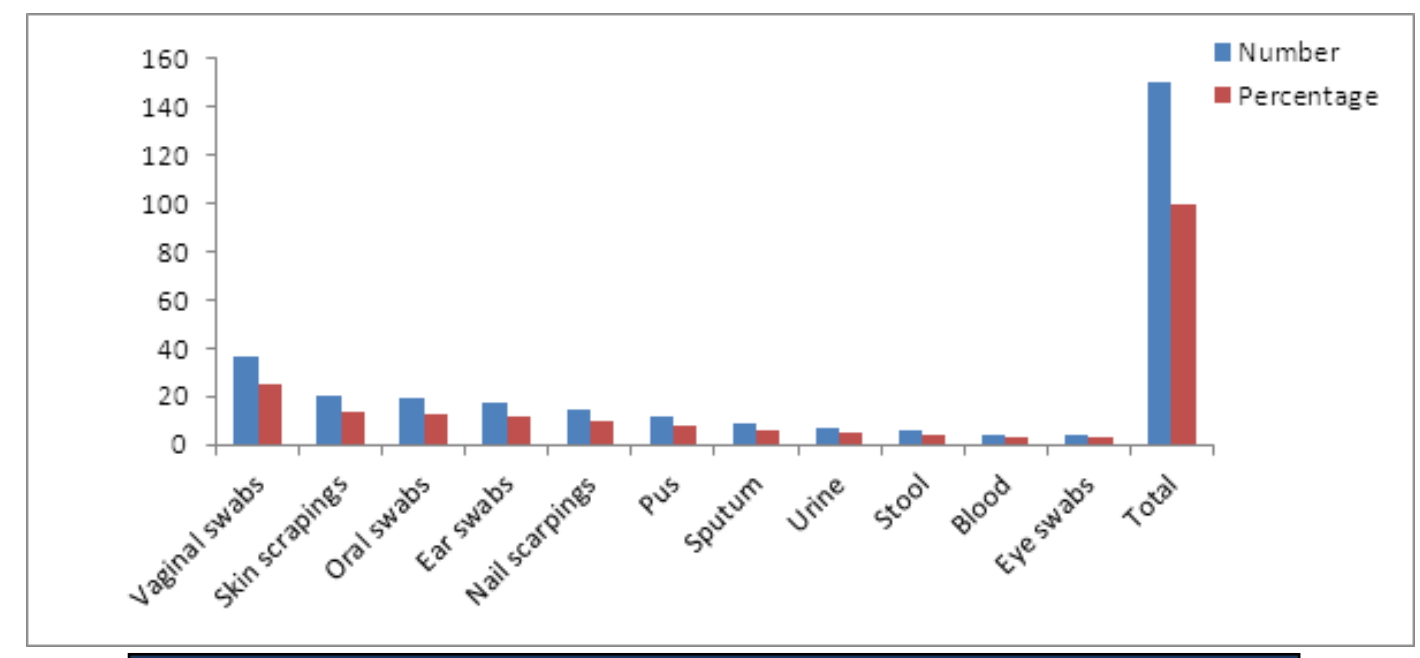

Fig. 1: Distribution of isolates among various Clinical specimens

In this study 83 were females, 67 were males (Table 1). 


\begin{tabular}{|c|c|}
\hline Sex & No. of Patients \\
\hline Male & 67 \\
\hline Female & 83 \\
\hline Total & $\mathbf{1 5 0}$ \\
\hline
\end{tabular}

Table 1: Distribution of Patients according to Sex

Among the 150 isolates 3 species are identified with predominance of C. albicans (119) followed by C. tropicalis (29) and C. guilliermondii (2) (Table: 2). It was noted that resistance of different species of candida was higher to fluconazole. The least resistance was seen with amphotericin- B (1.33\%) (Fig. 2).

\begin{tabular}{|c|c|c|c|c|}
\hline \multirow{2}{*}{ Sample } & \multirow{2}{*}{ No. } & \multicolumn{3}{|c|}{ Species } \\
\hline & & C. albicans & C. tropicalis & C. guilliermondii \\
\hline Vaginal swabs & 37 & 27 & 9 & 1 \\
\hline Skin scrapings & 20 & 15 & 5 & - \\
\hline Oral swabs & 19 & 14 & 5 & - \\
\hline Ear swabs & 17 & 12 & 5 & - \\
\hline Nail scrapings & 15 & 13 & 2 & - \\
\hline Pus & 12 & 10 & 2 & - \\
\hline Sputum & 9 & 8 & - & 1 \\
\hline Urine & 7 & 7 & - & - \\
\hline Stool & 6 & 6 & - & - \\
\hline Blood & 4 & 4 & - & - \\
\hline Eye swabs & 4 & 3 & 1 & - \\
\hline Total & 150 & 119 & 29 & 2 \\
\hline
\end{tabular}

\section{Table 2: Distribution of Different Candida among various Clinical Specimens}

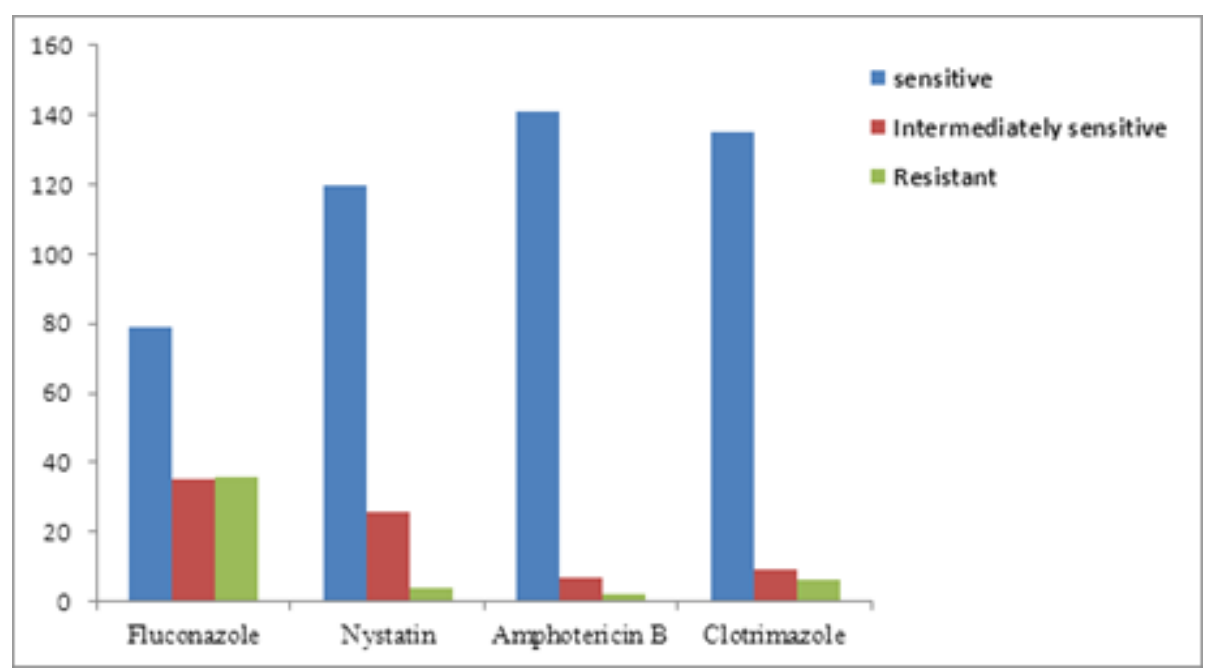

Fig. 2: Antifungal susceptibility patterns 
DISCUSSION: Candida is yeast like fungus which may cause acute or chronic, superficial or deep infection under certain predisposing factors. Recently the incidence of Candida infection has increased mainly because of HIV/AIDS. The present study showed that, highest number of samples were from vulvo-vaginitis (24.66\%). The other studies also showed similar results ${ }^{5}$. The most common isolate from all samples was C.albicans (79.33\%) followed by C.tropicalis (19.33\%) and C.guilliermondii (1.33\%). This correlates well with most of the other studies, with C.albicans as the predominant species ${ }^{6,7}$. According to a study conducted in 1978, it was found that higher incidence was in the females. In our study 83 were females, 67 were males. In this study most of the isolates of Candida sp. was sensitive to Amphotericin B (94\%) and resistance to Fluconazole (24\%) was higher compared to other drugs used. This is similar to the study by Pfaller et al. ${ }^{3}$ The presence of resistance to various antifungal agents emphasizes the need for routine susceptibility testing of candida.

CONCLUSION: This study highlights the need for rapid and specific identification of Candida isolates to species level for effective treatment and management. The periodic surveillance of antifungal susceptibility pattern of the prevalent Candida sp. is essential for the judicious use of antifungal drugs in patients.

\section{REFERENCES:}

1. Rippon J.W. Medical mycology, Philadelphia: WB Saunders, 1998.

2. Chander, Jagadish. Textbook of Medical Mycology. Ed.2. New Delhi: Metha, 2002.

3. Pfaller MA, JH Rex and MG Rinaldi. Antifungal susceptibility testing: technical advances and potential clinical applications. Clin Infect Dis 1997; 24 (May):776-84.

4. Chakrabarthi A et al. In vitro Antifungal susceptibility of candida. Indian J Med Res 1995; 102 (July): 13-19.

5. Karabinis Andreas et al. Risk factors for Candidemia in cancer patients: A case control study. J Clin Microbiol 1988; 26(3):429-32.

6. Kwon-Chung KJ, John E. Bennet. Medical Mycology, Philadelphia: Lea an Febiger, 1992.

7. Chakrabarthy A et al. Antifungal susceptibility pattern of non-albicans candida species and distribution of species isolated from candidemia cases over 5 years period. Indian J Med Res1996; 104 (Aug): 171-6.

\section{AUTHORS:}

1. Rudramurthy K. G.

2. Ramya Kumaran

3. Geetha R. K.

\section{PARTICULARS OF CONTRIBUTORS:}

1. Assistant Professor, Department of Microbiology, Karuna Medical College.

2. Tutor, Department of Microbiology, Karuna Medical College.

3. Professor and Head, Department of Microbiology, Karuna Medical College.

\section{NAME ADDRESS EMAIL ID OF THE} CORRESPONDING AUTHOR:

Dr. Rudramurthy K. G,

Assistant Professor,

Department of Microbiology,

Karuna Medical College, Vilayodi,

Palakkad, Kerala.

E-mail: rudramurthy.kargool@yahoo.com

Date of Submission: 06/02/2014.

Date of Peer Review: 07/02/2014.

Date of Acceptance: 14/02/2014.

Date of Publishing: 25/02/2014. 